\title{
The Rise of Aesthetic Anthropology in the Marginal Culture*
}

\author{
XIAO Qiong \\ Yunnan University of Finance and Economics, Yunnan, China
}

\begin{abstract}
At the turn of the century, the development of aesthetics encounters severe challenges and is trapped in a crisis. To get out of it, it is necessary to dig deeper in the study of aesthetics. The fact that the marginal areas' cultural heritage, agricultural culture, industrial culture and post-industrial culture often coexist in a harmonious way in a nation or the same area attracts the attention of aesthetic anthropologists. The paper mainly analyzes the constructive relationship between the culture of marginal areas and aesthetic anthropology, and discusses how to establish a relationship between them with the help of the development model of Yunnan's marginal culture.

Keywords: marginal culture, aesthetic anthropology, Yunnan’s marginal culture
\end{abstract}

At the turn of the century, the development of aesthetics encounters severe challenges and is trapped in a crisis. To get out of it, it is necessary to dig deeper in the study of aesthetics. The fact that the marginal areas' cultural heritage, agricultural culture, industrial culture and post-industrial culture often coexist in a harmonious way in a nation or the same area attracts the attention of aesthetic anthropologists and evokes their enthusiasm for the study of marginal culture. Therefore, it's inevitable that aesthetic anthropologists should search for the cultural traditions in the countryside to relieve the crisis aesthetics is in. With modern civilization declining, they attempt to find out a way leading to an ideal life in the future by means of tracking what primitive culture leaves behind. By directing their attention towards marginal culture and connecting modernity with tradition, they juxtapose the past, present and future of culture and seek to find out some internal mechanism to achieve the conversion of the three.

\section{The Rise of Aesthetic Anthropology: Culture Needs to Be Saved by Culture Itself}

Great civilization won't last forever. The modern Western civilization, which used to play a dominant role, is declining and seeking to save itself. Although the development of science and technology and the initiation of industrial civilization have brought human beings huge wealth, they have led to unprecedented mental deprivation and emptiness at the same time, which has in turn resulted in the confrontation between human beings and the world. Constantly materialized by modern technology, the integrity of people has suffered severe damage. And people's vitality has been seriously suppressed as well. Increasingly indifferent to each other, they feel lost and alienated. The infinite expansion of the Western civilization in material, together with the neglect of the spirits of human beings in its efforts to conquer nature, has led to the lack of relevant cultural notions and rules which can keep humans under restraint. Consequently, the balance between human and nature

\footnotetext{
* Acknowledgements: This paper was sponsored by China National Social Science Foundation "Research on the Fundamental Problems of the Contemporary Aesthetics and Criticism Patterns” (15ZDB023).

XIAO Qiong, a professor in the Institute of Media in Yunnan University of Finance and Economics. Her research field covers Marxism aesthetics and cultural theory.
} 
has been seriously disturbed and cultural changes and cultural fracture seem to have happened overnight. However, the modern civilization is unable to offer any remedy for the situation after stimulating human's insatiable desire for material. With human's subjectivity severely damaged, everybody has become a hollow man, having nothing but a body. All these force modern people to ponder over the new meaning and new concept of humans so as to meet their emotional needs and restore their original poetic wisdom and spiritual space. In fact, the loss of humanity should be attributed to culture and human beings' way of thinking. Since our ancestors climbed down from the tropical trees, we have left our habitats in the forest for good. And after building a culture independent of nature, we humans are no longer closely connected with nature. Since Descartes' day, we have been thinking of how to rule, control and conquer nature and preaching the paramount importance of human's subjectivity, damaging the harmony between human and nature.

But culture needs to be saved by culture itself. According to Kant's epistemological dualism, human's rationality has been exhausted. Consequently, they will inevitably go into reverse and begin to grasp the world with a holistic approach. People should not just see himself, but also should see their relationship with others. "The Other from which I borrow my speech tells me not only what I may say, but what I may desire; so that the most intimate core of my being is constituted by my relations to what I am not.” The Other can effectively inhibit the crazy self and provide an important frame of reference for ego. Lacan's theory of mirror stage tells us that people should try to recognize themselves using the other as a mirror and develop themselves with the power obtained from the other. Shu-xian Ye also found that the cultural other provides us with the best opportunity to identify our own defects and get rid of our egocentrism and stimulates reflective thinking most effectively. The narcissism of Western philosophy, aesthetics and psychology has been carried to the furthest extreme. Accordingly, it's recommended that the focus of study should be shifted towards Oriental culture to seek for a new model of cultural development. The Oriental culture has completely different symbols and psychological characteristics, as well as its own eternal working mechanism. It makes the interpersonal relationship, the relationship between human and nature and that between human and society its first priority, believing that harmony is very important for self improvement and development. "In China ... there is a fantasy related to the universal harmony brought about by the execution of some power. Although how the power is disposed is often enigmatic, it can legalize the social order of human society." Chinese culture is a kind of introverted culture, which sustains the external order by gradually influencing and changing people's inner world, and coordinating the interpersonal relationship invisibly, rather than resorting to idols for help. It guarantees social productivity and stability by making interpersonal relationship a part of ethics, while the Western culture is more pragmatic, focused on individual strength and human beings' conquest, transformation and utilization of nature rather than the harmony between nature and humanity. And the Western culture views things separately rather than from an overall perspective.

So Western culture, while advocating for human beings' power over nature, ignores the establishment of a harmonious relationship between human and nature and splits the integrity of man and nature. The Oriental culture, which lays an emphasis on universal love, altruism, reserve, mobility and other characteristics, can be an important frame of reference for the Western culture and can help it out of the culture development model that is based on the binary classification of the subject and the object and centered on self.

The unrestrained ruin of nature and expansion having eventually brought about disasters, Westerners feel shocked and realize that nature should no longer be split from culture. In fact, the secret of culture lies in nature, and the secret of nature in culture. Eagleton conducted a study of "culture" by examining its etymological root 
and drew the conclusion that "culture" is derived from nature, not the other way round. In the English language the word "culture" originally meant "the raising of plants or animals", "Originally the word 'culture' was related to nothing but material. Later it was used figuratively to refer to something spiritual.” Therefore, to reach inner balance, humans are bound to create or seek other cultures for spiritual adjustment and compensation. Western civilization, which stresses the importance of reason, critical thought and metaphysics but lacks an empirical foundation, has come to an end, whereas perceptual thinking, featuring spiritual relaxation and poetic imagination, is full of vitality. Reason and perception, which used to be antithetical to each other, now has fused. And today's aesthetic anthropologists are trying to find a way to combine Western civilization and oriental culture. It turns out that culture needs to be saved by culture itself.

\section{The Focus of the Marginal Culture and Its Transformation}

According to Levi Strauss, there are two kinds of culture, the industrial civilization in modern society which interprets the world with reason and conceptions, and the culture in a natural form that is based on science and defines the world perceptually and comprehensively. This is the characteristics of primitive culture. This mode of mythical thought, called sporadic art by Levi Strauss, always sees history and society as some dispersed materials. It mixes all these materials together and creates new structures with the mixture. But the ability to define everything perceptually and comprehensively lays a foundation for all civilizations, without which both humans and human society will lose their balance.

In his Economic and Philosophic Manuscripts of 1844, Marx put forward the central concept of anthropology, that is, human is not a social or cultural being, but "exists in the form of classes", "nature is the direct object of scientific study", and "the first object of human's scientific study is nature”, which illustrates the close correspondence between man and nature. However, the fact is that the dominant theories are established on the notion that humans and animals, and cultures and nature are separated from and opposing to each other. Today, only the primitive cultures in some marginal areas remain close to nature. In the development of China's unique traditional culture, it's the ordinary people and their simple, primitive, loose but effective folk culture that truly carry forward the traditional civilization. Human's culture consciousness can be divided into three levels: the first level is the primitive folk custom; the second are the disciplines extracted from the folk customs; and the third is philosophy, the study of nature and meaning of the universe and human life. "In terms of the structure of culture consciousness, folk custom in its original form"; "Folk custom is the first step on the ladder of cultural awareness ... the foundation and pillar of cultural ideology"; "It's a mixture of culture and life". In the long history of the development of human culture consciousness, the folk customs constitute its prototype image and lay a foundation for the reason and realistic tendency of human culture awareness. Folk culture is undoubtedly an important cultural representation which plays an irreplaceable intermediary role in the structure of human culture.

The marginal culture still maintains its original state. Isolated from the mainstream culture, and free of political influence, the marginal culture not only keeps its tradition intact, but has greater intrinsic compatibility and potential for development. Because of its location, the marginal culture has not been strongly influenced by modern civilization. People here still cling to nature, depend on nature, and even submit to nature completely. The natural production mode, restricted by the primitive ecological environment, has led to the stability of the economic structure and the convergence of cultural mentality. Each ethnic group has its own religion, totem worship, rituals and myths, representing their fear and awe of nature. 
The preservation of the original cultural relics in the marginal area is a miracle of human civilization. The residents in the area usually do not receive a good education. They even do not have their own written language. But they have great wisdom and creativity to inherit, improve and pass on their culture in their own way. For example, some scriptures of Dongba culture are preserved thanks to the amazing memory of several elderly people, who can keep the scriptures in mind and recite them.

The simplicity and harmony shown by the marginal cultures have attracted the attention of aesthetic anthropologists. Aesthetic anthropology studies and interprets aesthetic issues and phenomena with the anthropological method and the conceptual system. It compares and contrasts different races and ethnic groups in aesthetic habits, aesthetic system and aesthetic tradition based on field studies. Aesthetic anthropology emphasizes the importance of the empirical method and field research and abandons subjective factors. And it asks anthropologists to go deep into the cultural environment itself, gain an insight into the ethnic group's traditions and experience, and interpret traditional cultures in a modern context. "The core of aesthetic anthropology research is the aesthetic practice of specific ethnic groups and the creative achievements they have made".

The Western culture has long been in a dominant position, which has naturally restrained the development of the culture of the ethnic minorities. Therefore aesthetic anthropology focuses more on the cultural phenomena and aesthetic experience neglected or not fully appreciated in the past, especially the cultures of ethnic groups. It interprets the positive and healthy ways of aesthetic communication of the minority cultures and reveals their obscure cultural notions and aesthetic perception.

Anthropologists have conducted a lot of field investigations into the folk customs enthusiastically, trying to gain an insight into the cultural phenomena and find the inner running mechanism of the primitive cultures. However, anthropologists' penetration into the original culture in the marginal area, which used to be isolated from the outside world, together with the new things and new ideas in its wake, has inevitably led to cultural conflicts, which has in turn led to cultural changes. The ideology and thinking modes inside the traditional culture are undergoing some changes. The younger generations have accepted new things quickly. For example, the traditional folk costumes now are just worn on some festive occasions. And the society cannot be restored to its original pattern.

The preservation and modern transformation of the primitive cultures in today's society needs to be pondered seriously. Fortunately, thanks to their flexibility and openness, primitive cultures are able to adjust themselves accordingly and quickly.

\section{The Development Strategies and Strategic Choice of the Marginal Culture in Yunnan}

At present, in spite of being an underdeveloped province in the southwest part of China, Yunnan has made great progress in its reform of the cultural system and cultural industry on the basis of its rich resources of ethnic culture and active development of its cultural industry such as the ethnic cultural tourism and ethnic festivals, which has drawn much attention and applause from China and abroad. Yunnan is a province with its unique ethnic culture that has hosted many large-scale jubilee shows like the original dancing show "Yunnan Image" and "Yunnan Week of Culture and Economy" as was held in France and so on. In other words, as an underdeveloped province in China's West, Yunnan has really explored and established a new and unique mode of development which is different from the economically developed areas in the East of China. However, there is the problem of protecting and passing on the marginal culture and ethnic culture, which is confronting the 
marginal culture as a dilemma at present. From my perspective, there are altogether three most widely accepted modes of protection so far as follows:

Forms of festivals: "festival cultures are embodied in all kinds of cultural activities, cultural products, cultural services and cultural atmosphere while having the specific psychology, morality, spirits, values and aesthetics of these ethnic minorities as its cultural essence. Meanwhile, festival cultures are actually a kind of social cultural phenomenon with specific themes and are laid out in specific time and places." Nowadays, festival culture functions as the most effective way of protecting marginal cultures in modern society. Some festivals like folklore festivals and kite festivals are on the rise in its development and are gradually gaining people's attention. These festivals have served as an important conveyor of the marginal culture by passing on the aesthetic and cultural spirits of these ethnic groups due to their rich ethnic traditions, rituals, trends, psychology and ideas specific to these minority groups. According to the theory of Bakhtin, festivals usually result from carnivals when people will dance and sing to understand the implied meaning of cultures and to experience the collision and fusion of the traditional ideas with modern consciousness. Therefore, being an aesthetic culture and an activity of appreciating cultures, these colorful ethnic festivals have constituted a kind of culture with its unique implications. These festivals, with their vivid images, forceful representation and profound emotions, lead us to a deep-felt encounter with the typical atmosphere and contents of the history and forms of their cultures.

In Yunnan, there are altogether 25 different ethnic minorities with their distinct social structure, social forms and various traditional cultures due to their different geographical environment, ways of production and lifestyles as well as ethnic beliefs. There are also numerous ethnic festivals in Yunnan, such as torch festival, flowers festival, water-splashing festival, the dragon festival, gourd festival of Lahu, and Hani's Angmatu festival, etc. It is exactly these unique festivals that have helped to bring about the prosperity of Yunnan's national culture, to enhance the unity of cultural identities between minority groups, and to attract the modern people to appreciate its aesthetic form and performance, thus promoting the development and prosperity of the national culture.

However, with many ethnic festivals developing until today, their connotation and forms have undergone great changes. The original functions of these festivals have been extended and the contents of these festivals have also been further generalized, thus leading to its change from the primitive religious worships to the aesthetic entertainment. Meanwhile, the enhancement of the commercial consciousness has resulted in the commercialization of some ethnic festivals to adjust to the needs of the society. The cultural contents and aesthetic pursuit embedded in these festivals have gradually got weaker and finally got lost in the whole process, which really needs to call for attentions and reflections while we are immersed in the apparent splendor of the festival culture.

Development and tourism: Modern tourism, as a form of modern consumption, is actually a phenomenon that is worthy of our in-depth study. People in the modern society, tired of the noises of the city and the hypocrisy in human relationships, look forward to a quiet place which can give vent to the free expression of their spirits. The marginal culture of these areas, because of the detachment of it from the main-stream metropolitan culture, keeps their own individuality and characteristics. This simple and harmonious relationship displayed in these cultures appeals greatly to the people in the cities. As a result, reasonable development of these marginal areas and effective introduction of tourism will on the one hand protect our traditional culture and on the other hand enhance people's understanding of the traditional cultures. What's more, these can bring 
comfort to people in big cities by bringing peace to their hearts and promote the development of the economy in these areas. The book entitled Chinese Folklore, Tourism Series goes like this in its preface: the tourists are not content with simply enjoying the natural scenery; they need to know more about the society. Advanced (high-level) tourism is usually a special form of academic activity. Inspired by the spectacular scenery of the places and the rich spiritual and material heritage of the ethnic groups there as well as the actual visual impact of the historical, natural and cultural phenomena there, tourists can extend and broaden their minds by the meditation of many issues that are far beyond their present existence.

Yunnan has ranked among the top in the development of tourism in China. Yunnan has set it as a priority to develop the ethnic tourism in the construction of the rural areas by focusing on the promotion of the performance and marketing of the folk arts and crafts as well as the development of ethnic culture tourism, etc. Meanwhile, it plans to actively carry out the activities such as "the township of culture", "the township of art", and "the township of crafts" with an eye to promoting on a large scale the specialized development of "One Town One Product”, “One Village One Product”, which will eventually lead to the establishment of a unique brand of cultural products, the development of its ethnic cultural industry and the realization of its optimal economic benefits.

However, it is essential that we should be prudent in developing the industry of ethnic culture. First of all, there is a paradox in this industry itself. For one thing, its quick rise and prosperity goes together with the trend of cultural industry; for another, the industry of ethnic culture has its own ethnic, regional, empirical and original characteristics. Therefore, focusing on the economic profits and neglecting its symbolic significance and aesthetic benefits as the result of equating its management with that of other ordinary industries or commodities, will surely risk putting the regional aesthetic experiences out of its context. For example, after the inscription of Liiangyan Cultural Heritage, excessive tourist and commercial development of the city has almost induced the loss of this ancient town's individuality.

Ever since 1993 the writer has been to Lijiang several times and witnessed the transformation of this city from a refreshing old town to a lifeless "circus ground". For example, the majority of the former citizens of the town have been replaced by the businesses from the outside world, with the streets flooding with crowds of noisy travelers, which leads to the disappearance of a self-contented old town and the extinction of a thousand-year-history traditional lifestyle. Just as the folk named Nasi said "Lijiang is dead." As a result, with the gradual disappearance of the traditional architecture, festival culture, the costume culture and folk arts, the old town of Lijiang has been gradually overpowered by the outside culture and commercialization. Therefore, it is vital that we remain rational while reveling in the tremendous economic benefits brought about by this regional ethnic culture.

We need to take into consideration the fact that we should do all that we can to keep the sustainable development of the national industry while developing the national cultural industry, publicizing the traditional culture and achieving economic benefits, which obviously calls for the involvement of the intellectuals and aesthetic anthropologists.

Just as professor Wang Jie has commented after his in-depth research and rational thinking about the minority group called Heiyizhuang in Guangxi province as a scholar, due to the lack of the subjectivity and initiative of the ethnic minorities, the Heiyizhuang ethnic groups have reaped disappointment and identity crisis in spite of their enthusiasm after mistakenly setting commercial development and economic benefits as the motivation of the development of their culture. All this took place as the result of the great impact of the 
outside world and the lure of economic benefits in the wake of the government's efforts to market this cultural brand. Scholars have also drawn conclusions from their anthropological studies and research that we must try to get back to track our studies and research of the modern aesthetic value of the folk arts of the ethnic minorities by combining the protection and development of the cultural resources of the arts of the ethnic minorities with their transformation. In other words, we need to keep a balance between the aesthetic value and the practical value of the arts of the ethnic minorities and therefore base the commercial development and governments' use of the arts on the integrity of the aesthetic experiences of the local ethnic minorities. This will eventually call for the in-depth meditation about the way we promote various cultural brands and activities, which means integrating our way of expressing feeling and experiencing the world with our habits and aesthetic experiences.

The field research and in-depth exploration: As a cultural elite group, the anthropologists are approaching the same goal in different directions when confronted with the increasingly open state of the marginal culture. They did a lot of field research as well as empirical studies, and laid great emphasis on participation and observation. They made an analysis of the ethnography by the experts of anthropology following the principle of truthful, multi-angle and comprehensive integrity. They delve deep into and draw pictures of the real situation of the culture in their studies on the basis of empirical research through the use of philosophy and aestheticism. They pave the way for a deeper understanding of the essence of the ancient culture and the differences between cultures. They give voice to the things that have not been expressed or do not need expressions in writing, thus helping people understand the significance of the ancient culture directly from writing and therefore invoking people's sense of protection and give guidance to the transformation of ancient traditional culture in the modern society.

\section{Conclusion}

Therefore, there is a heavy responsibility on the shoulders of the aesthetic anthropologists and a long way ahead in their pursuit. On the one hand, they're obliged to acquire a confronting power by way of explaining, identifying and referring to the traditional ancient culture; on the other hand, they're bound to give expression to the rich traditional culture through their writing, thus avoiding plunging into the trap of Western centralism. The marginal culture integrates real life with idealism and lays various cultures in parallel. As a result, marginal culture opens the door to a dialogue between tradition and modernism and offers a cultural system which helps humans gain its self-knowledge and self-reflection, and finally a referential system of life in face of human confusion and bewilderment.

\section{References}

China National Book Festival. (1993). Beijing: Knowledge Publishing.

Karl Marx. (1979). Economic \& Philosophic Manuscripts of 1844. Beijing: People’s Publishing.

Terry Eagleton. (2000). The Idea of Culture. UK: Blackwell Publishing Ltd.

Terry Eagleton. (2003). Sweet Violence: The Idea of the Tragic. UK: Blackwell Publishing Ltd.

Terry Eagleton. (2009). Trouble With Strangers: A Study of Ethics. Oxford: Wiley-Blackwell. 